\title{
A concepção socialista da educação e os atuais paradigmas da qualificação para o trabalho: Notas introdutórias
}

\author{
Rosemary Dore Soares*
}

\begin{abstract}
RESUMO: A literatura educacional brasileira inspirou-se nas idéias socialistas para apresentar propostas alternativas para a escola. No entanto, o socialismo real entrou em crise. Viria essa situação abalar os ideais socialistas de uma escola para todos? Neste texto, argumenta-se que o socialismo real, devido às suas contradições internas, não foi, no Brasil, referência para o debate sobre a concepção socialista da escola. Este fundamentou-se mais na filosofia política do socialismo do que na prática concreta das sociedades do leste europeu. No entanto, o conceito socialista da escola, tanto quanto antes da débâcle do socialismo real, permanece confuso. A unidade das formações geral e técnica, tema relevante desse ideário, vem sendo retomada em face de demandas contemporâneas do capitalismo, no campo da qualificação profissional, exigindo novas pesquisas sobre o assunto.
\end{abstract}

Palavras-chave: qualificação para o trabalho, concepção socialista de educação, crise do socialismo real, novas tecnologias, impactos sobre educação

Introdução

Um veio pouco discutido na nossa literatura educacional refere-se à análise do conceito socialista de educação no quadro das tendências do novo ordenamento mundial, onde se configura a crise do "socialismo real".

A "nova ordem mundial" pode ser caracterizada, em grandes linhas, pelo fim da guerra fria e pela queda do "socialismo real" no leste europeu; pela crise do Estado do bem-estar social (modelo social-democrata) e pela ascensão do pós-liberalismo, ${ }^{1}$ com as estratégias para o soerguimento do capitalismo, aliadas à introdução da microeletrônica no processo produtivo, provocando enormes impactos em todas as esferas da vida social.

* Professora da Faculdade de Educação da Universidade Federal de Minas Gerais. 
Esse conjunto de mudanças tem apontado para uma questão paradoxal: no mesmo momento em que o "socialismo real" entra em crise, os novos paradigmas de organização do trabalho, surgidos com o desenvolvimento de novas tecnologias, recolocam o ideal de unidade entre as formações técnica e científica, reativando o debate sobre a concepção socialista da educação, consubstanciada na proposta da "escola unitária". Tal é a tendência indicada por alguns educadores, segundo os quais a "escola unitária" estaria ganhando força no próprio capitalismo (Saviani 1994; Paiva 1990).

Por que se trata de uma questão paradoxal? Primeiro, porque o ideal de unidade da escola não é novidade no capitalismo, pois a "escola nova" foi uma proposta apresentada com esse objetivo (Soares 1992). Segundo, porque esse ideal não se concretizou no capitalismo, em face das suas contradições sociais que dividem a sociedade em governantes e governados, nem no "socialismo real", cujos conflitos próprios não possibilitaram realizar o princípio da igualdade social, inerente ao conceito de "unitário" (Gramsci 1978b, p. 125). De que novas condições dispõe hoje a sociedade capitalista para implementar a "escola unitária"?

Paradigmas da nova filosofia do trabalho e concepção socialista da escola

Sob diferentes abordagens, seja no campo da sociologia da educação ou da filosofia da educação, por exemplo, muitos pesquisadores têm procurado investigar os nexos entre as recentes transformações econômicas, sociais, políticas e ideológicas e o fenômeno educativo. A preocupação dominante nessas investigações tem se revelado na busca do entendimento da natureza das mudanças operadas na produção capitalista e nas políticas educacionais formuladas pelo modelo de atuação do Estado pós-liberal. ${ }^{2}$

As reflexões sobre as relações existentes entre as grandes tendências da "nova ordem mundial" e a qualificação educacional mostram que as inovações tecnológicas exercem impactos sobre a educação ao exigir: aquisição de possibilidades de pensamento teórico, abstrato; capacidade de analisar, pensar estrategicamente, planejar e responder com criatividade a situações novas; capacidades sociocomunicativas para desenvolver trabaIho cooperativo em equipe; conhecimentos ampliados que possibilitem a independência profissional (Paiva 1990, p. 111). A grande maioria das análises sobre a relação entre qualificação educacional e atividade produtiva 
aponta para o seguinte fenômeno: a exigência de elevar a escolaridade do trabalhador, articulando-se formação geral e técnica e rejeitando-se o predomínio da especialização, que vigorou até recentemente (Carvalho 1994; Hirata 1994; Saviani 1994; Assis 1994; Pinto 1992; Segnini 1992; Castro 1992; Market 1991 e 1992; Baethge 1989; Paiva 1995).

A exigência dessa nova qualificação, entretanto, vem sendo associada a dois motivos contraditórios: elevar a produtividade do capital e responder aos conflitos operários, verificados nos anos 60 . O enriquecimento das tarefas, forjando o trabalhador polivalente, foi um modo de superar os problemas advindos das lutas operárias contra o trabalho parcelado e repetitivo (Coriat 1978, p. 110), que se manifestavam em greves, absentismo, processos de sabotagem etc. (Ruffier 1978, p. 56). A lutas sindicais não tinham como finalidade apenas o aumento salarial. Elas também questionavam a própria organização do trabalho na fábrica (Borzeix 1978, p. 256). A rebelião dos operários levou o empresariado a refletir sobre os custos econômicos do trabalho do ponto de vista da humanização do trabalho, da democracia industrial, da reforma da empresa, da melhoria das condições de trabalho, do enriquecimento das tarefas, da formação de equipes autônomas (ibid., 1978, p. 257).

A nova filosofia das relações industriais surge, assim, num contexto contraditório. Ela resulta da luta dos trabalhadores contra o capitalismo e da estratégia dos empresários para neutralizar os conflitos trabalhistas (Saccardo e Lino 1986, p. 94), adaptando os processos produtivos às atuais condições de concorrência do mercado.

Chamou-me a atenção um veio pouco discutido na literatura educacional que focaliza essas transformações do mundo moderno. Trata-se da análise sobre a concepção socialista da educação no quadro das tendências desse novo ordenamento mundial. Embora possa ser considerado polêmico e controverso falar de uma concepção socialista da educação, existem algumas pontuações que ajudam a esclarecer esse tema.

O estudo do desenvolvimento histórico da concepção socialista da educação, na literatura educacional brasileira, é recente. Ele foi surgindo na medida em que alguns educadores começaram a buscar, no "campo teórico socialista", fontes de esclarecimento para fundamentar a formulação de projetos democráticos de educação para a sociedade.

A noção de "campo teórico socialista" pode ser entendida como o referencial teórico-metodológico fundado no marxismo, com base no qual foram elaboradas historicamente concepções diferenciadas para a crítica do mundo capitalista e do "socialismo real". ${ }^{3}$ Trata-se, assim, de um 
campo epistemológico muito vasto e heterogêneo, que se ampliou depois da crise do stalinismo (1956), dando origem ao desaparecimento de qualquer "ortodoxia" internacional, dominante ou obrigatória (Hobsbawm 1989, p. 49).

Das reflexões sobre os problemas econômicos, sociais, políticos e ideológicos do capitalismo, emergiram perspectivas teóricas e práticas para construir uma nova sociedade, que contribuíram para fundamentar tanto a leitura das questões educacionais quanto a apresentação de propostas para enfrentar os desafios da educação na sociedade em que vivemos.

O nível de complexidade e polêmica desse "campo teórico socialista" foi aprofundado depois dos impactos que a crise verificada nas sociedades socialistas do leste europeu exerceu sobre a filosofia e a prática do socialismo. Em que medida esses impactos vêm atingindo a análise da sociedade hoje e o encaminhamento de propostas democráticas para a organização escolar?

Em primeiro lugar, é preciso levar em conta que, antes da crise do "socialismo real", o "campo teórico socialista" gerou as mais diferentes análises da escola na sociedade capitalista e das possíveis soluções para seus problemas (de Marx a Gramsci, passando por Althusser 1974).

Em segundo lugar, não se pode considerar que o colapso do "socialismo real" tenha levado à crise do marxismo, pois a discussão dessa temática já é "clássica" na história do pensamento contemporâneo. ${ }^{4}$

Mas a implosão das sociedades do leste europeu veio reforçar pelo menos três grandes correntes de pensamento, ainda que contraditórias entre si: a) a que critica o marxismo a partir de uma ótica liberal para legitimar o capitalismo; b) a que critica o marxismo sugerindo uma revisão de paradigmas sem propor a adesão ao capitalismo tardio; c) a que procura desenvolver o marxismo numa perspectiva histórico-crítica.

Essa última linha de reflexão crítica do "socialismo real" encontrou em Gramsci um de seus mais destacados representantes. Ela constituiu o campo teórico gerador de novos conhecimentos sobre as relações entre o Estado e a sociedade civil no mundo contemporâneo, abrindo espaços para analisar a questão cultural, limitadamente enfocada no pensamento socialista de matriz economicista. Esse novo veio de investigação abriu vastas possibilidades de interpretar o fenômeno educativo no conjunto dos processos sociais, articulando-o a possibilidades concretas de transformação da sociedade. 
A questão metodológica mais importante a ser ressaltada nesse novo entendimento do fenômeno educativo é a crítica cerrada ao viés economicista na análise da relação entre Estado e sociedade, tendência que prevaleceu no marxismo (Andreucci 1982, p. 23). O estudo aprofundado das reflexões de Gramsci permitiu compreender que a desestruturação dos regimes do leste europeu, nas últimas décadas do século XX, era a culminância de um processo iniciado nos anos 20 . A sustentação de um governo apenas na força contrariava as mais antigas premissas da ciência política, formuladas desde Maquiavel, segundo as quais toda forma de poder deve combinar força e consenso (Gramsci 1976 , p. 138). Essa foi a referência adotada pelas democracias ocidentais que, nem por isso, deixaram de dominar os trabalhadores na busca de realizar objetivos da acumulação capitalista.

As reflexões de Gramsci sobre as relações entre Estado e sociedade contribuíram, portanto, para questionar a idéia de que a cultura estava direta e imediatamente subordinada à economia. Sob essa orientação foram realizadas análises sobre nossa organização escolar, com o objetivo de apresentar propostas para sua transformação, ainda na sociedade capitalista. Entretanto, mesmo que muitas dessas análises partissem de concepções gramscianas, elas chegaram a conclusões díspares sobre a constituição da escola no capitalismo tardio. ${ }^{5}$

A interpretação mais divulgada foi a de que a organização escolar surgida das lutas sociais do início deste século - a "escola nova" se opunha aos anseios das massas populares, devendo ser inteiramente repudiada. ${ }^{6}$ Essa análise da escola nascia da crítica ao determinismo, presente em análises que foram hegemônicas nos anos 70, conhecidas como concepções "reprodutivistas". Entretanto, por rejeitar radicalmente a "escola nova", sem identificar nas suas contradições internas possibilidades de superar seus limites, tal análise crítica acabava, paradoxalmente, reforçando o enfoque "reprodutivista". Foi essa problemática que motivou a pesquisa teórica que realizei na tese de doutorado (Soares 1992). Meu objetivo foi o de retomar a trajetória lógica e histórica da crítica gramsciana ao economicismo e sistematizar sua reflexão sobre o Estado e a escola.

O resgate da teoria gramsciana do Estado e de suas reflexões sobre a educação permitiu compreender que sua proposta de "escola unitária" foi desenvolvida a partir das contradições da "escola nova", constituindo-se como instrumento para enfrentar a hegemonia desta última no mundo ocidental. Sua característica fundamental é a de propor 
uma escola igual para todos, fundada na unidade das formações científica e técnica, que se encontram cindidas na organização dualista da escola. Nesse sentido, ela procura superar as concepções existentes no socialismo, como a "escola politécnica" (Marx 1974) e a "escola única do trabalho" (Lenin 1977; Krupskaia 1977). A primeira foi pensada como estratégia para enfrentar a "escola tradicional", inspirando-se nas novidades surgidas por ocasião da revolução da indústria, na segunda metade do século XIX. A segunda foi concebida como estratégia para enfrentar a própria "escola nova", no início deste século.

No entanto, os limites corporativistas do movimento operário impediram que a "escola única do trabalho" fosse estruturada a partir de uma perspectiva de conquista da hegemonia pelo proletariado. Ela se manteve dentro de limites classistas, fundada numa perspectiva meramente tática e não estratégica, da qual está ausente a noção de hegemonia. Desse modo, ela não se apresentou como referência para superar projetos excludentes e particularistas, como os que têm marcado as realizações do capitalismo no campo educacional. Já a "escola unitária" se insere numa outra perspectiva: uma escola para todos, sob a hegemonia do projeto cultural socialista (Soares 1992). É importante ressaltar que as concepções de Gramsci não foram vitoriosas no movimento operário, pois não apoiavam a linha política stalinista, que prevaleceu no movimento operário a partir de 1928-1929, sustentando uma visão fatalista e determinista da transformação social. Por isso, suas idéias só começam a ser divulgadas, na Europa, ${ }^{7}$ depois da crise do stalinismo em 1956 e, no Brasil, nos anos $80 .^{8}$

A partir do momento em que foram acirradas as críticas às análises sobre o papel da educação pública no país, fundadas nas teorias de Althusser (1974), que se mostravam incapazes de oferecer alternativas para a organização democrática da escola, alguns educadores brasileiros se interessaram em aprofundar a análise da concepção socialista da educação (Savianni 1989; Franco 1987; Kuenzer 1985; Paoli 1980, dentre outros). Mas a tendência dominante nos debates instaurados nos meios acadêmicos foi a de excluir a análise das experiências educacionais do "socialismo real".

O "socialismo real", antes mesmo da débâcle do final dos anos 80 , vinha evidenciando uma profunda crise, manifesta nos planos político, econômico e cultural. No plano político, a limitação da iniciativa popular e do pluralismo, desde a ascensão de Stalin, inviabilizou a constituição de uma sociedade civil atuante, reforçando a incompatibi- 
lidade entre socialismo e democracia. Isso marcou a política de repressão às tentativas de "liberalizar" o socialismo, como ocorreu no levante húngaro de 1956, na Primavera de Praga, em 1968. No plano econômico, a ausência de democracia impediu a inovação e o desenvolvimento de associações de trabalhadores e o intercâmbio entre trabalhadores qualificados e pesquisadores científicos (Blackburn 1993, p. 162). Essa tendência, aliada ao esforço econômico gigantesco, imposto pela corrida armamentista e por toda a estratégia militar dos anos da "guerra fria", dificultou a modernização do parque industrial interno, incapacitando os países do leste europeu a acompanhar o desenvolvimento tecnológico do ocidente (Barros 1988, p. 70). No plano cultural e filosófico, a negação de direitos civis e políticos refletiu-se sobre a "inércia" cultural dos países comunistas, onde a ausência da crítica e do debate impediu a renovação de idéias, favorecendo a difusão de um marxismo fossilizado e dogmático. Por essas características, o "socialismo real" vinha sendo objeto da crítica de largos setores da esquerda, que não viam nessa experiência paradigmas mais elevados para a crítica das complexas democracias do ocidente.

Conseqüentemente, a organização da escola no "socialismo real" também não poderia ser considerada um parâmetro para a análise e a crítica da escola capitalista. Por isso, ela não constituiu um referencial teórico consistente para formular princípios educativos, em bases socialistas, que orientassem propostas educacionais democráticas no ocidente. Grande parte dos intelectuais de esquerda, envolvidos com a questão escolar, foi buscar elementos para fundamentar a reflexão sobre o conceito socialista de educação nos autores clássicos, tais como Marx, Engels, Lenin, Gramsci. Assim, o debate que se instalou no Brasil a respeito da idéia socialista de escola, nos anos 80 , inspirou-se, predominantemente, no socialismo como "filosofia" política e não como prática concreta. As experiências que chegaram a ser mencionadas pela literatura educacional situavam-se na extrema periferia do "socialismo real", nas sociedades mais atrasadas da África e da América Central (Moçambique, Guiné Bissau, Cuba).

O fato de a experiência escolar do "socialismo real" não ter se mostrado relevante para fundamentar a proposição de políticas educacionais democráticas poderia nos levar a uma conclusão importante: a "queda do muro" no leste europeu não deveria ter impactos de peso sobre a concepção socialista da educação. No entanto, o estudo dessa concepção não pode prescindir de uma análise da organização escolar no "socialismo real", pois sem uma "âncora" na realidade concreta a idéia socialista de educação não poderia ser criticada e desenvolvida. 
Se as interpretações sobre a "escola nova" são diversificadas e muitas vezes conflituosas entre si, o mesmo ocorre a respeito da concepção socialista da educação. A propósito desta última, é expressivo o depoimento de Frigoto ao reivindicar o aprofundamento da tese da "escola unitária", assinalando que, nesse campo, onde os debates são recentes, os "mal-entendidos são muitos" (Frigoto 1993, p. 41, grifo nosso).

Quando se aponta hoje para os liames entre a "escola unitária" e a idéia de "polivalência", surgida a partir das novas tendências do capitalismo, chamadas de "não-tayloristas" ou "pós-fordistas", é preciso perguntar: De que concepção socialista da educação está se falando?

Seria a "escola politécnica" o mesmo que a "escola unitária"? Qual seria a especificidade da atual proposta de "polivalência"? Por que a concepção socialista da educação estaria sendo reforçada justamente no contexto de crise do "socialismo real"? Em que essa crise e as tendências da "nova ordem mundial" redimensionam a idéia da "escola unitária"?

Mas se a "escola unitária", nascida como concepção educacional no "campo teórico socialista", propunha enfrentar a "escola nova", ela ainda se manteria hoje capaz de ser uma referência para ser contraposta às tendências apresentadas pelas novas demandas do capitalismo que vêm se consubstanciando na proposta de "escola polivalente"?

Os desafios colocados por essa problemática estão exigindo a busca de novos elementos teóricos. Nessa direção têm-se encaminhado as pesquisas que atualmente venho desenvolvendo, na tentativa de encontrar respostas para essas questões. ${ }^{9}$

\section{Notas}

1. Discutindo o significado do neoliberalismo, o professor Saviani afirma que ele correspondeu ao período inaugurado com a derrota da Comuna de $\mathrm{Pa}$ ris, quando o capitalismo de monopólios se foi consolidando e os conceitos centrais do liberalismo clássico foram reformulados para incorporar reivindicações de teor socialista. Já os princípios econômicos e políticos atualmente em voga, como o incentivo à redução das políticas sociais e as privatizações das empresas estatais, não correspondem ao conteúdo próprio do neoliberalismo. Por isso, o autor prefere incluí-los no conceito de "pós-liberalismo" (Saviani 1992, pp. 25-28).

2. Essa é a tendência apontada por Silva quando argumenta que os atuais debates sobre as relações entre as novas tecnologias e a educação têm 
se limitado ao estudo do processo de trabalho, deixando de "problematizar as relações mais amplas existentes entre a produção da ciência e da tecnologia e o processo de produção capitalista" (Silva 1993, p. 23). Relações essas que não estão circunscritas no local do trabalho.

3. A partir do final dos anos 50, teve início um movimento de renovação do marxismo, tanto nas sociedades capitalistas quanto no "socialismo real", com o surgimento de dissidências com o marxismo soviético. Segundo Hobsbawm, é nesse quadro que se insere a idéia de "pluralismo" no marxismo: "Por mais que algumas teorias elaboradas por alguns marxistas suscitem a suspeita e a hostilidade de outros, é difícil encontrar hoje um consenso difuso, em nível internacional ou nacional, sobre o que constitui uma interpretação legítima e o que, de fato, deixa de ser 'marxista'. Tudo isto é particularmente evidente em campos como a filosofia, a história e a economia" (Hobsbawm 1989, p. 49).

4. Contestando o velho modo de falar em "crise do marxismo", Carlos Nelson Coutinho pergunta: "De qual marxismo?" Recorda que o marxismo tem uma história que "não é apenas uma série de 'desvios' em relação a uma pretensa 'verdade revelada' e/ou mera sucessão de 'aplicações' mais ou menos bem-sucedidas dessa 'verdade', mas um esforço permanente de superação dialética de posições que se tornaram anacrônicas ou se revelaram equivocadas" (Coutinho 1985, pp. 7-8).

5. É o caso das interpretações de Saviani e Nosella sobre o surgimento da "escola nova". Para o primeiro, esta escola foi criada pela burguesia imperialista e serviu, fundamentalmente, para desarticular os movimentos populares (Savianni 1985, pp. 56-57). Para o segundo, a "escola nova" tem originalmente um caráter progressista porque foi organizada pelo movimento operário, durante a Comuna de Paris. Depois, ela foi apropriada pela burguesia, que the deu um feitio conservador (Nosella 1986, pp. 120 e 131).

6. Essa é a conclusão a que chegam Saviani, quando propõe retomar a "escola tradicional" como estratégia para construir sua pedagogia revolucionária (Savianni 1985, pp. 60-62), e Nosella, quando propõe o retorno à pedagogia dos militantes da Comuna de Paris (Nosella 1986, p. 134).

7. Segundo Santarelli, o pensamento de Gramsci começou a ser retomado na Itália somente depois da queda do fascismo. Mas o primeiro volume de sua obra só foi publicado após a crise de 1956 (Santarelli 1991, p. 13).

8. Desde o final dos anos 60 , já vinham sendo divulgados entre nós alguns livros de Gramsci, dentre os quais Os intelectuais e a organização da cultura. Essa obra, de grande importância para a reflexão sobre a educação e a escola, só chamou a atenção dos intelectuais de esquerda nos anos 80.

9. Dentre elas, situa-se $A$ escola unitária e o papel da filosofia da educação na nova ordem mundial, que vem sendo realizada com o apoio do CNPq. 
The socialist concept of education and the current paradigms of the qualification to work: Some questions

ABSTRACT: The Brazilian educational literature was inspired by socialist ideas to present alternative scholastic proposals. However real socialism fell into crisis. Will this situation affect the socialist ideals about a quality public school for everybody? In this text we support the argument that real socialism, owing to its inherent contradictions, did not give references, in Brazil, to the debate on a socialist concept of education. This was influenced more by the political philosophy of socialism than by the concrete practise of the societies of eastern Europe. However, the socialist concept of school remains today as confused as it was before the débâcle of real socialism. Actually, the unity of general and technical education that is the relevant theme on this conception is again undergoing demands of capitalism in the field of professional qualification, so requiring new research on the subject.

\section{Bibliografia}

ANDREUCCI, Franco. "A difusão e a vulgarização do marxismo". In: Hobsbawm, E.J. (org.). História do marxismo: O marxismo na época da Segunda Internacional. Rio de Janeiro, Paz e Terra, 1982, vol. 2, pp. 15-74.

ALTHUSSER, Louis. Ideologia e aparelhos ideológicos do Estado. Lisboa, Presença, 1974.

ASSIS, Marisa de. "A educação e a formação profissional na encruzilhada das velhas e novas tecnologias". In: Ferreti, C.J. et al. (orgs.). Novas tecnologias, trabalho e educação: Um debate multidisciplinar. Petrópolis, Vozes, 1994, pp. 185-199.

BAETHGE, Martin. "Novas tecnologias, perspectivas profissionais e autocompreensão cultural: Desafios à formação (Bildung)". In: Educação e Sociedade Ano X, São Paulo, Cortez, dez. 1989, pp. 7-26.

BARROS, Edgard L. A guerra fria: A aliança entre russos e americanos. As origens da guerra fria: A destruição atômica é irreversível? São Paulo, Atual; Campinas, Editora da Universidade Estadual de Campinas, 1988.

BLACKBURN, Robin. "O socialismo após o colapso". In: Blackburn, R. (org.) Depois da queda: O fracasso do comunismo e o futuro do socialismo. Rio de Janeiro, Paz e Terra, 1993, pp. 107-215. 
BORZEIX, A. "Les syndicats et l'organisation du travail". In: Linhart R. et al. Division du travail. Paris, Galileé, 1978, pp. 255-267.

CARVALHO, R.Q. "Capacitação tecnológica, revalorização do trabalho e educação". In: Ferreti, C.J. et al. (orgs.). Novas tecnologias, trabaIho e educação: Um debate multi disciplinar. Petrópolis, Vozes, 1994, pp. 93-123.

CASTRO, Nadya A. "Organização do trabalho, qualificação e controle na indústria moderna". In: Machado, L. et al. Trabalho e educação. Campinas, Papirus/Cedes; São Paulo, Ande/Anped, 1992, pp. 69-86.

CORIAT, B. "Differenciation et segmentation de la force de travail dans les industries de process". In: Linhart, R. et al. Division du travail. Paris, Galileé, 1978, pp. 109-124.

COUTINHO, C.N. Gramsci. Porto Alegre, L\&PM, 1981.

. A dualidade de poderes: Introdução à teoria marxista de Estado e revolução. São Paulo, Brasiliense, 1985.

DADOY, M. "La polyvalence ouvrière et sa remuneration". In: Linhart, R. et al. Division du travail. Paris, Galileé, 1978, pp. 81-92.

FRANCO, Antonio de Carvalho. A escola do trabalho e o trabalho da escola. São Paulo, Cortez, 1987.

FRIGOTTO, G. "Trabalho e educação: Formação técnico-profissional em questão". Universidade e sociedade (5). São Paulo, Andes, 1993, pp. 38-42.

GRAMSCI, Antonio. L'alternativa pedagogica. Florença, La Nuova Italia, 1975.

- Maquiavel, a política e o Estado moderno. Rio de Janeiro, Civilização Brasileira, 1976.

. Pasado y presente. Barcelona, Granica, 1977a.

. Quaderni del carcere. Turim, Einaudi, 1977b, 4 vols.

Concepção dialética da história. Rio de Janeiro, Civilização Brasileira, 1978a.

Os intelectuais e a organização da cultura. Rio de Janeiro, Civilização Brasileira, 1978b. 
HIRATA, Helena. "Da polarização das qualificações ao modelo da competência". In: Ferreti, C.J. et al. (orgs.). Novas tecnologias, trabalho e educação: Um debate multidisciplinar. Petrópolis, Vozes, 1994, pp.124-138.

HOBSBAWM, E.J. "O marxismo hoje: Um balanço aberto”. In: Hobsbawm, E.J. (org.). História do marxismo: O marxismo hoje. Rio de Janeiro, Paz e Terra, 1989, vol. 11, pp. 13-100.

KRUPSKAIA, N. "Papel de Lenin na luta por uma escola politécnica". In: Lenin, V.I. Sobre a educação. Lisboa, Seara Nova, 1977, vol. 2, pp. 167-173.

KUENZER, Acácia. Pedagogia da fábrica: As relações de produção e a educação do trabalhador. São Paulo, Cortez, 1985.

. Sobre a educação. 2 vols., Lisboa, Seara Nova, 1977.

LENIN, V.I. La instrución pública. Moscou, Progreso, 1975.

MAGNOLI, Demetrio. Da guerra fria à détente: Política internacional contemporânea. Campinas, Papirus, 1988.

MARKET, Werner. "Novas formas de trabalho e de cooperação na empresa. Possibilidades de formação do indivíduo e desenvolvimento de competência de formação do ambiente". In: Educação e Sociedade $\mathrm{n}^{\circ}$ 36. São Paulo, Vértice, 1991, pp. 13-30.

" "Revendo o trabalho como princípio educativo à luz da experiência alemã”. In: Machado, L. et al. Trabalho e educação. Campinas, Papirus/Cedes; São Paulo, Ande/Anped, 1992, pp. 103-112.

MARX, Karl. El capital: Crítica de la economia política. Livro I. México, Fondo de Cultura Económica, 1974.

MATTOSO, J.E. "Notas sobre a terceira revolução industrial, crise e trabalho no Brasil”. In: Soares, R.M. (org.). Gestão da qualidade: Tecnologia e participação. Brasília, Codeplan, 1992, pp. 179190.

NOSELLA, Paolo. "Educação tradicional e educação moderna: Debatendo com Saviani”. In: Educação e Sociedade nº 23. São Paulo, Cortez, abril 1986 .

. "Produção e qualificação para o trabalho: Uma revisão da bibliografia internacional”. In: Dias, Fernando Correia (org.). Ensino das humanidades: A modernidade em questão. São Paulo, Cortez; Brasília Seneb, 1991, pp. 19-103. 
PAIVA, Vanilda."Produção e qualificação para o trabalho". In: Franco, M.L. e Zibas, D. (orgs.). Final do século. São Paulo, Cortez, 1990, pp. 95-122.

"Inovação tecnológica e qualificação". In: Educação e Sociedade nํ50. Campinas, Papirus, 1995, pp. 70-92.

PAOLI, N.I. Ideologia e hegemonia. São Paulo, Cortez/Autores Associados, 1980.

PINO, Ana Maria de Rezende. "Pessoas inteligentes trabalhando com máquinas ou máquinas inteligentes substituindo o trabalho humano". In: Machado, L. et al. Trabalho e educação. Campinas, Papirus/ Cedes; São Paulo, Ande/Anped, 1992, pp. 25-38.

RUFFIER, J. "L'enrichissement des taches: Une reponse a la pression ouvrière". In: Linhart, R. et al. Division du travail. Paris, Galileé, 1978, pp. 47-58.

SACCARDO, Cleusa e LINO, Helio F.C. "Novas técnicas de organização e a tecnologia no capitalismo". In: Bruno, Lúcia e Saccardo, Cleusa (orgs.). Organização, trabalho e tecnologia. São Paulo, Atlas, 1986, pp. 89-100.

SALERNO. "Trabalho e organização na empresa industrial integrada e flexível". In: Ferreti, C.J. et al. (org.). Novas tecnologias, trabalho e educação: Um debate multidisciplinar. Petrópolis, Vozes, 1994, pp. 54-76.

SANTARELLI, E. "L'eredità politica e la fortuna letteraria di Antonio Gramsci". In: Santarelli, E. (org.). Gramsci ritrovato (1937-1947). Catanzaro, Abramo, 1991, pp. 9-80.

Escola e democracia. São Paulo, Cortez, 1985.

SAVIANI, Dermeval. "Tendências e correntes da educação brasileira". In: Mendes, Durmeval Trigueiro (org.). Filosofia da educação. Rio de Janeiro, Civilização Brasileira, 1983.

Sobre a concepção de politecnia. Rio de Janeiro, Fundação Oswaldo Cruz, 1989.

"Neoliberalismo ou pós-liberalismo? Educação pública, crise do Estado e democracia na América Latina". In: Velloso, J.; Mello, G.N.; Wachowicz, L. e outros. Estado e educação. Campinas, Papirus/Cedes; São Paulo, Ande/Anped, 1992, pp. 9-29. 
"O trabalho como princípio educativo frente às novas tecnologias". In: Ferreti, C.J. et al. (orgs.). Novas tecnologias, trabalho e educação: Um debate multidisciplinar. Petrópolis, Vozes, 1994, pp. 147-164.

SEGNINI, L.R. "Controle e resistência nas formas de uso da força de trabalho em diferentes bases técnicas e sua relação com educação". In: Machado, L. et al. Trabalho e educação. Campinas, Papirus/Cedes; São Paulo, Ande/Anped, 1992, pp. 59-68.

SILVA, T. Tadeu. "As novas tecnologias e as relações estruturais entre educação e produção". In: Cadernos de Pesquisa nº 87 . Fundação Carlos Chagas, São Paulo, Cortez, 1993, pp. 20-30.

SOARES, Rosemary D. "A concepção gramsciana do Estado e o debate sobre a escola". Tese de doutoramento. São Paulo, PUC, 1992, mimeo. 